\title{
Recycling of Cobalt by Liquid Leaching from Waste 18650-Type Lithium-Ion Batteries
}

\author{
Liangmou Yu1, Bo Shu'², Shiwen Yao \\ ${ }^{1}$ Faculty of Environmental Engineering, Kunming Metallurgy College, Kunming, China \\ ${ }^{2}$ Yunnan Copper Co., Ltd., Kunming, China \\ Email: xiashubiao401@163.com
}

Received 25 July 2015; accepted 22 August 2015; published 25 August 2015

Copyright (C) 2015 by authors and Scientific Research Publishing Inc.

This work is licensed under the Creative Commons Attribution International License (CC BY).

http://creativecommons.org/licenses/by/4.0/

(c) (†) Open Access

\begin{abstract}
In this work, we recover cobalt from waste 18650-type lithium-ion batteries by acid leaching. The cathode material is completely dissolved, after leaching waste batteries by using $10 \mathrm{~mol} / \mathrm{L}$ industrial sulfuric acid at $70^{\circ} \mathrm{C}$ for $1 \mathrm{~h}$. The rate of cobalt leaching is nearly $100 \%$. Removal of sodium carbonate, iron, aluminum and other impurities from the leaching solution was well performed by adjusting the $\mathrm{pH}$ to $2-3$ with stirring vigorously. Finally, under the conditions of $55^{\circ} \mathrm{C}-60^{\circ} \mathrm{C}$ of 240 $\mathrm{A} / \mathrm{m}^{2}$ current density, electrodeposition current efficiency was $90.01 \%$, the quality of the electrical output achieved cobalt $1 \mathrm{~A}$ standard electrolytic cobalt, cobalt until greater than $90 \%$ yield. The process is easy and suitable for large-scale lithium-ion batteries used in the recovery of valuable metals.
\end{abstract}

\section{Keywords}

Component, Cobalt, 18650-Type Lithium-Ion Battery, Leaching, Electrodeposition

\section{Introduction}

Rechargeable lithium-ion batteries as a new generation of green, non-pollution chemical energy storage device are widely used in portable electronic apparatus and vehicles. However, waste LIBs contain heavy metals, organic chemicals and plastics, which will bring environmental pollution. Therefore, the recycling of major components from spent LIBs is considered to be a beneficial way to prevent environmental pollution and as alternative resource of cobalt [1]. 18650-type power batteries are widely used in small portable devices, increasing along with the rise of electric vehicles in Tesla [2]. The spent lithium ion batteries contain 5 - 15 wt.\% cobalt and 2 - 7 wt.\% lithium as important constituents, which are an active cathodic material. The waste 18650 type lithium ion batteries contain precious metal elements cobalt with a certain toxicity as important constituents, which are an active cathodic material. Since cobalt is a relatively expensive material compared to the other battery constituents and can be widely used in new LiBs electrode materials, its recovery is one of the primary ob- 
jectives in the recycling of spent batteries [3] [4]. Figure 1 is a 18650 type battery price polyvalent metallic element [5]. It is not difficult to see from Figure 1 that the price of the cobalt is more expensive than the other battery constituents. Therefore the recovery and utilization of cobalt have significant economic and social environmental benefits [6].

Separation and Recovery Technology 18650 cobalt lithium ion battery mainly includes three steps: 1) the waste batteries discharge, stripped shell, simple crushing, after screening to obtain an electrode material, or simply crushed after firing to remove organic matter to obtain an electrode material [7]; 2) the material obtained in the first step of the electrode is dissolved in the leaching of various metals into solution wherein both the cobalt and nickel represent as trivalent forms. Leaching sub-step dissolution method and two-dissolution method: direct step by acid leaching dissolution method, all the metal was dissolved in acid, and then isolated using a number of different purification and recovery; two-step method is to use an alkali leaching aluminum and recovered, and then use acid leaching surplus metal oxide, followed by the similar treatment as the first step [8];3) the solution (leachate) dissolved metal elements in the solution is separated for recycling or direct synthesis anode material. Separation and recovery methods are chemical precipitation, salting out, ion exchange, extraction, electrochemical method, respectively cobalt or lithium-containing compound [9]. E.M.S. Barbieri et al. [10] have investigated recycling cobalt from the cathodes of spent $\mathrm{Li}$-ion batteries as $\beta$-Co(OH $)_{2}$, obtaining $\mathrm{Co}_{3} \mathrm{O}_{4}$. $\beta-\mathrm{Co}(\mathrm{OH})_{2}$ with a hexagonal structure by using chemical precipitation or electrochemical precipitation. This method does not directly recovered cobalt. In this paper, we recovered directly cobalt by electrodeposition.

\section{Experimental}

Experimental material: Waste 18650 lithium-ion battery, industries concentrated sulfuric acid, industrial grade sodium borate. Hand split waste 18650 lithium-ion batteries, remove the interior material with pliers, and finally the positive and negative material separated and dried $24 \mathrm{~h}$ at $60^{\circ} \mathrm{C}$. The obtained positive electrode material with $10 \mathrm{~mol} / \mathrm{L}$ sulfuric acid leaching $1 \mathrm{~h}$, and filtered to give leachate. Spectrophotometric determination of $\mathrm{Co}^{2+}$ concentration in the solution (722S spectrophotometer, Shanghai Precision Scientific Instrument Co., Ltd.) with cobalt ions spectral qualities, using X-ray diffraction (Japan Rigaku company DM/ax-IIIA) salting crop products phase analysis. Process is shown in Figure 2, ICP analysis content of the test solution of various metal elements.

\section{Results and Discussion}

\subsection{Effect of $\mathrm{pH}$ on the Leaching Process}

When the solution of sulfuric acid concentration is too low, even at boiling temperature, leaching reaction is also extremely slow. Therefore, the leaching temperature was set at $70^{\circ} \mathrm{C}$, under the conditions of the reaction time of $1 \mathrm{~h}$, acidity leaching test, the results shown in Figure 3 shows that, as the solution acidity increase, cobalt and

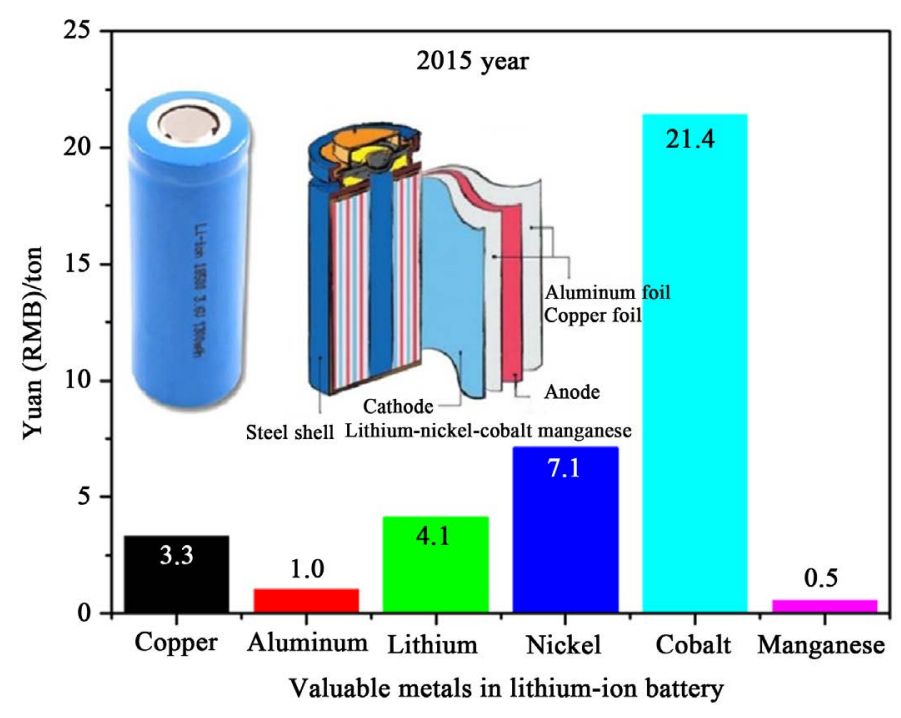

Figure 1. Price metal elements contained at 18650 lithium-ion batteries. 


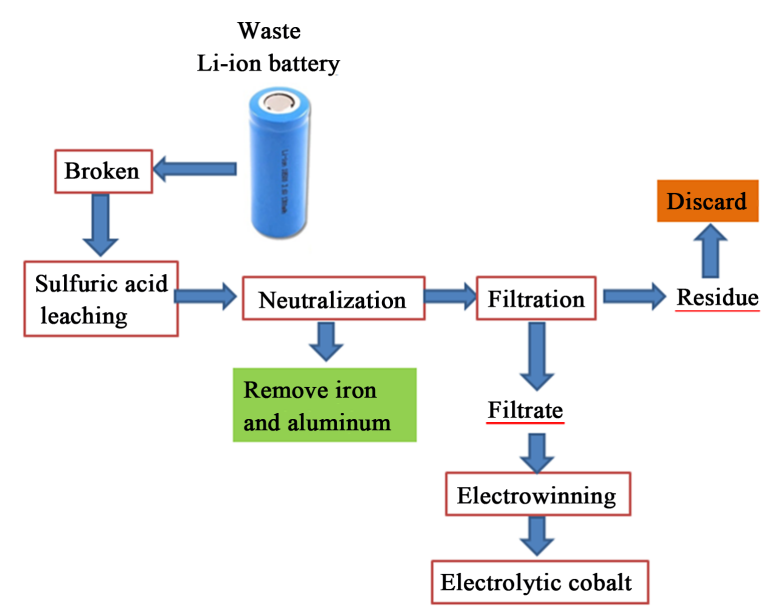

Figure 2. Process flow diagram of cobalt recovery by liquid leaching.
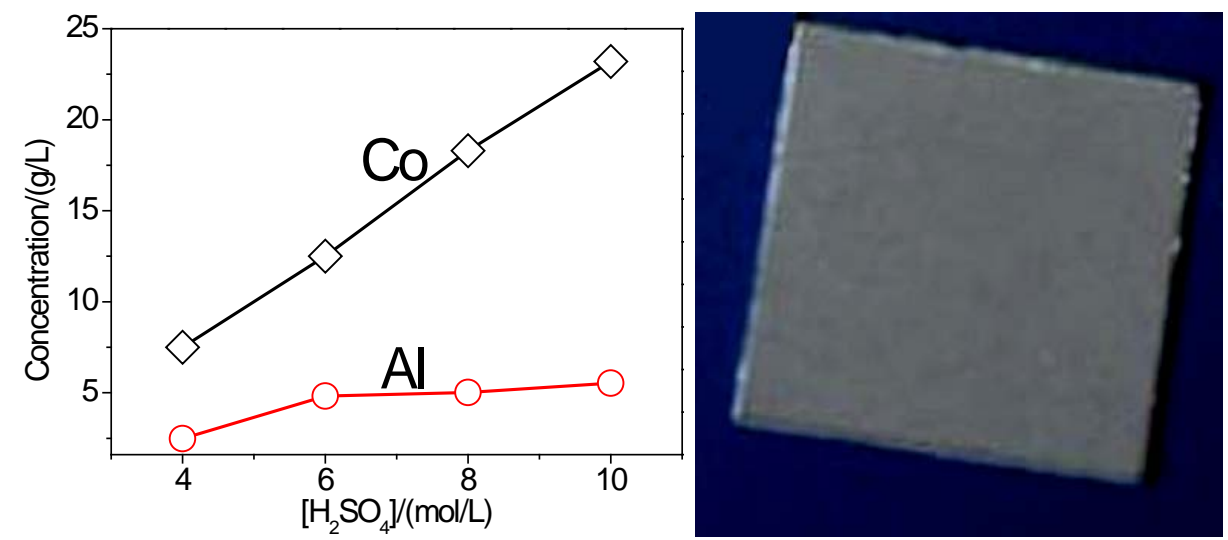

Figure 3. Effect of acid concentration on leaching rate and electrolytic cobalt photo.

aluminum solubility in the solution increases accordingly. With $10 \mathrm{~mol} / \mathrm{L}$ sulfuric acid solution as an industrial leaching agent, the lithium-ion battery with the waste placed in $5 \mathrm{~L}$ beaker, heated to $70^{\circ} \mathrm{C}$, leaching $1 \mathrm{~h}$, the reaction was completely dissolved, ICP testing the resulting solution composition shown in Table 1.

\subsection{Neutralization Reaction to Remove Iron, Aluminum}

Leaching with sodium carbonate as a neutralizing agent resulting solution was adjusted to $\mathrm{pH} 2-3$, and heated to $90^{\circ} \mathrm{C}$, blast stirred solution of iron and aluminum precipitate. At the same time, also co-precipitation in the form of silicon is removed. After hydrolysis impurity solution composition shown in Table 2.

$$
\begin{aligned}
& 2 \mathrm{Fe}^{3+}+3 \mathrm{CO}_{3}^{2-}=\mathrm{Fe}_{2}\left(\mathrm{CO}_{3}\right)_{3} \downarrow \\
& 2 \mathrm{Al}^{3+}+3 \mathrm{CO}_{3}^{2-}=\mathrm{Al}_{2}\left(\mathrm{CO}_{3}\right)_{3} \downarrow
\end{aligned}
$$

\subsection{Electrodeposition}

Starting with the production of cobalt cathode pole piece, a titanium plate as an anode, the impurity resulting solution directly electrowinning current density of $240 \mathrm{~A} / \mathrm{m}^{2}$, electrolyte temperature $55^{\circ} \mathrm{C}-60^{\circ} \mathrm{C}$, in return anolyte electrolysis and cleaning section the resulting electric cobalt surface roughness, the spectral analysis of its components, such as tables, Table 3, Figure 3 also lists the quality standards 1 and $1 \mathrm{~A}$ \# \# electric cobalt electric cobalt [11].

Table 3 shows full-immersion neutralized after hydrolysis direct electrowinning cobalt impurity, product quality can be made $1 \mathrm{~A}$ electric cobalt standards. The electrolytic cobalt electricity obtained by the Formula (3) 
Table 1. Content of each metal element in leaching solution.

\begin{tabular}{ccccccc}
\hline Element & $\mathrm{Co}$ & $\mathrm{Ni}$ & $\mathrm{Li}$ & $\mathrm{Al}$ & $\mathrm{Cu}$ & $\mathrm{Fe}$ \\
\hline Content $(\mathrm{g} / \mathrm{L})$ & 23.67 & 0.022 & 1.72 & 6.10 & 0.001 & 0.004 \\
\hline
\end{tabular}

Table 2. Content of each metal element in leaching solution after neutralization reaction to remove iron, aluminum.

\begin{tabular}{ccccccc}
\hline Element & $\mathrm{Co}$ & $\mathrm{Ni}$ & $\mathrm{Li}$ & $\mathrm{Al}$ & $\mathrm{Cu}$ & $\mathrm{Fe}$ \\
\hline Content $(\mathrm{g} / \mathrm{L})$ & 47.12 & 0.033 & 2.84 & 0.01 & 0.001 & 0.001 \\
\hline
\end{tabular}

Table 3. Cathode cobalt quality and criterion of GB6517-86.

\begin{tabular}{cccc}
\hline \multirow{2}{*}{ Element } & \multicolumn{3}{c}{ Content (Impurities $\leq$ Co $\geq$ ) $/ \%$} \\
\cline { 2 - 4 } & Electrolytic cobalt by experiment & Standard of Co 1 & Standard of Co1A \\
\cline { 2 - 4 } $\mathrm{Mn}$ & 99.88 & 99.98 & 99.65 \\
$\mathrm{Fe}$ & 0.0005 & 0.001 & 0.01 \\
$\mathrm{Ni}$ & 0.001 & 0.003 & 0.05 \\
$\mathrm{As}$ & 0.051 & 0.005 & 0.2 \\
$\mathrm{~Pb}$ & 0.001 & 0.0005 & 0.001 \\
$\mathrm{Cu}$ & 0.0004 & 0.0003 & 0.001 \\
$\mathrm{Si}$ & 0.001 & 0.001 & 0.02 \\
$\mathrm{Al}$ & 0.001 & 0.001 & - \\
\hline
\end{tabular}

obtain the current efficiency of the electrolysis process $90.01 \%$.

$$
\eta=G /(q \cdot A \cdot t \cdot n)=460 /(1.1 \times 4 \times 116 \times 1) \times 100 \%=90.01 \%
$$

where: $\eta$ — current efficiency, \%; $G$-precipitation Electric Co Quality, $g$; $q$-cobalt electrochemical equivalent, $1.1 \mathrm{~g}$ Ah; $A$-current intensity, $A$; $t$ —electrolysis cycle, $h$; $n$ —cell number. Direct yields greater than $90 \%$ cobalt.

\section{Conclusion}

The use of sulfuric acid leaching-EW treatment of waste lithium 18605 lithium-ion battery technologies is simple. Cobalt leaching rate basically reached $100 \%$, absolute yield of more than $90 \%$. Leach solution after hydrolysis impurity can be directly electrowinning cobalt, simple process. We get 1A \# electric cobalt comply GB651786 by electrolyte. The current efficiency was $90.01 \%$.

\section{References}

[1] Debaraj, M., Kim, D.-J., Ralph, D.E., et al. (2008) Bioleaching of Metals from Spent Lithium Ion Secondary Batteries Using Acidithiobacillus ferrooxidans. Waste Management, 28, 333-338.

[2] Jin, Y.-J., Mei, G.-J. and Li, S.-Y. (2006) Study on Cobaltous Recovery from Cathode Leachate of Lithium-Ion Battery by Salting Out. Acta Scientiae Circumstantiae, 26, 1122-1125. (In Chinese)

Wang, X.-F., Kong, X.-H. and Zhao, Z.-Y. (2001) Rcovery of Metal in Lithium ion Battery. Battery Bimonthly, 31, 14-15. (In Chinese)

[3] Nan, J.-M., Han, D.-M., Cui, M., et al. (2004) Recycling of Valuable Metal from Spent Li-Ion Batteries by Solvent Extraction. Battery Bimonthly, 34, 329-311. (In Chinese)

[4] Lupi, C., Pasquali, M. and Dell'Era, A. (2005) Nickel and Cobalt Recycling from Lithium-Ion Batteries by Electrochemical Processes. Waste Management, 25, 215-220. http://dx.doi.org/10.1016/j.wasman.2004.12.012 
[5] Wang, C.-Y., Qiu, D.-F., Chen, Y.-Q., et al. (2004) Status of Spent Batteries Recovery and Recycle. Nonferrous Metals, 5, 39-42. (in Chinese)

[6] Xie, G.Y., Ling, Y. and Zhong, S. (2009) Overview of Recovery Techniques of Spent Lithium-Ion Batteries. Environmental Science \& Technology, 32, 97-101.

[7] Li, J.H., Shi, P.X., Wang, Z.F., et al. (2009) A Combined Recovery Process of Metals in Spent Lithium-Ion Batteries. Chemosphere, 77, 1132-1136. http://dx.doi.org/10.1016/j.chemosphere.2009.08.040

[8] Sun, L. and Qiu, K.Q. (2011) Vacuum Pyrolysis and Hydrometallurgical Process for the Recovery of Valuable Metals from Spent Lithium-Ion Batteries. Journal of Hazardous Materials, 194, 378-384.

[9] Li, L., Ge, J., Wu, F., et al. (2010) Recovery of Cobalt and Lithium from Spent Lithium Ion Batteries Using Organic Citric Acid as Leachant. Journal of Hazardous Materials, 176, 288-293.

[10] Barbieri, E.M.S., Lima, E.P.C., Lelis, M.F.F., et al. (2014) Recycling of Cobalt from Spent Li-Ion Batteries as $\beta$ $\mathrm{Co}(\mathrm{OH})_{2}$ and the Application of $\mathrm{Co}_{3} \mathrm{O}_{4}$ as a Pseudocapacitor. Journal of Power Sources, 270, 158-165. http://dx.doi.org/10.1016/j.jpowsour.2014.07.108

[11] Zhao, J.M., Shen, X.Y., Deng, F.L., et al. (2011) Synergistic Extraction and Separation of Valuable Metals from Waste Cathodic Material of Lithium Ion Batteries Using Cyanex272 and PC-88A. Separation and Purification Technology, 78, 345-349. http://dx.doi.org/10.1016/j.seppur.2010.12.024 